\title{
Entrando en materia: novela, poesía y cultura material en El ruido de las cosas al caer
}

The Heart of the Matter: Novel, Poetry, and Material Culture in The Sound of Things Falling

Entrando em matéria: romance, poesia e cultura material em EI ruido de las cosas al caer ( $O$ barulho das coisas ao cair)

\section{Aníbal González}

YALE UNIVERSITY, ESTADOS UNIDOS

Profesor del Departamento de Español y Portugués de Yale University, Estados Unidos. PhD en Literatura por la misma Universidad. Autor de La crónica modernista hispanoamericana (Porrúa Turanzas, 1983), La novela modernista hispanoamericana (Gredos, 1987), fournalism and the Development of Spanish American Narrative (Cambridge University Press, 1993), Abusos y admoniciones: ética y escritura en la narrativa hispanoamericana moderna (Siglo XXI, 2001; versión al inglés: Killer Books: Violence, Writing, and Ethics in Modern Spanish American Narrative; University of Texas Press, 2002), A Companion to Spanish American Modernism (Támesis, 2007), Love and Politics in the Contemporary Spanish American Novel (University of Texas Press, 2010) y una edición comentada de la novela Redentores de Manuel Zeno Gandía en la Editorial de la Universidad de Puerto Rico (2010). Correo electrónico: anibal.gonzalez@yale.edu 


\section{Resumen}

Este artículo reflexiona sobre el papel simbólico de los objetos materiales en la novela El ruido de las cosas al caer, de Juan Gabriel Vásquez, y su relación con las referencias a la poesía en el texto. El ensayo argumenta que esta novela examina los límites de la representación realista en la novela e invita al lector a una reflexión sobre el carácter móvil y fluido de las cosas, los objetos que nos rodean, los cuales - pese a su materialidad - no necesariamente constituyen puntos de apoyo firmes para la construcción de un relato veraz. La poesía surge entonces en el seno de la novela como un elemento añadido que intenta suplementar la "fluidez" de las cosas mediante el artificio de la forma poética.

Palabras clave: Juan Gabriel Vásquez; cosas; Martin Heidegger; José Asunción Silva; Aurelio Arturo; literatura colombiana

\section{Abstract}

This article reflects on the symbolic role of material objects in Juan Gabriel Vásquez's novel The Sound of Things Falling, and its relation to the references to poetry in the text. The essay argues that this novel examines the limits of realist representation in the novel, and invites readers to reflect about the mobile and fluid nature of objects, of the things that surround us, which despite their materiality do not necessarily constitute a firm basis for constructing a believable story. Poetry appears then in the midst of the novel as an added element that tries to supplement the "fluidity" of things by means of the artifice of poetic form.

Keywords: Juan Gabriel Vásquez; things; Martin Heidegger; José Asunción Silva; Aurelio Arturo; Colombian literature

\section{Resumo}

Este artigo reflete sobre o papel simbólico dos objetos materiais no romance El ruido de las cosas al caer, de Juan Gabriel Vásquez, e seu relacionamento com as referências à poesia no texto. $\mathrm{O}$ ensaio argumenta que este romance examina os limites da representação realista no romance e convida o leitor para uma reflexão sobre o caráter móvel e fluído das coisas, os objetos que nos rodeiam, os quais - pese a sua materialidade - não necessariamente constituem pontos de apoio firmes para a construção de um relato veraz. A poesia surge então no seio do romance como elemento aderido que intenta suplementar a "fluidez" das coisas mediante o artificio da forma poética.

Palavras-chave: Juan Gabriel Vásquez; coisas; Martin Heidegger; José Asunción Silva; Aurelio Arturo; literatura colombiana

\section{Cómo citar este artículo:}

González, Aníbal. "Entrando en materia: novela, poesía y cultura material en El ruido de las cosas al caer". Cuadernos de Literatura 20.40 (2016): 477-489. http://dx.doi.org/10.11144/Javeriana.cl20-40.emnp 
"Un gran novelista es alguien que se da cuenta de más cosas". RITA DE MAESENEER Y JASPER VERVAEKE, "UN FÓSFORO EN LA OSCURIDAD"

\begin{abstract}
"Las cosas viejas, tristes, desteñidas, sin voz y sin color, saben secretos de las épocas muertas, de las vidas que ya nadie conserva en la memoria,

y a veces a los hombres, cuando inquietos las miran y las palpan, con extrañas voces de agonizante dicen, paso, casi al oído, alguna rara historia que tiene oscuridad de telarañas, son de laúd, y suavidad de raso". JOSÉ ASUNCIÓN SILVA, "VEJECES"
\end{abstract}

"Todas las distancias, en el tiempo y en el espacio, se encogen". MARTIN HEIDEGGER, "LA COSA"

DESDE SUS INICIOS en la temprana modernidad, la novela ha centrado su atención en el mundo de las cosas y a las cosas de este mundo: desde los molinos de viento, los mazos de batán y el baciyelmo del Quijote hasta los interiores domésticos burgueses, atiborrados de objetos manufacturados, de la novela realista decimonónica. El siglo XIX, dijo E. M. Forster, fue "la era de la propiedad" y las novelas de esa época abundaban en un amontonamiento de cosas, un aparente horror al vacío (citado en Brooks 15). También, como nos recuerda Peter Brooks, el realismo novelesco planteaba que no se podía:

[...] representar a las personas sin tomar en cuenta las cosas que las personas utilizan y adquieren para definirse a sí mismas — sus herramientas, sus muebles, sus accesorios. Estas cosas son parte de la definición misma del "carácter", de lo que uno es y de lo que uno dice ser. La presencia de las cosas en estas novelas marca además la ruptura con la tradición estilística del neoclásico, que tendía a ver lo concreto, lo particular y lo utilitario como algo vulgar, de clase baja, y que buscaba la belleza en lo generalizado y lo noble (16). ${ }^{1}$

Por su parte, la narrativa vanguardista europea de principios del siglo XX procuró romper con la manía realista de la descripción minuciosa de ambientes y objetos en favor del enfoque sobre la interioridad psíquica o, como lo dijo Virginia Woolf,

1 Todas las traducciones en este ensayo son mías, a no ser que se indique lo contrario. 
la representación de "an ordinary mind on an ordinary day" ("una mente ordinaria en un día ordinario" [106]). Sin embargo, pese a las preferencias semejantes de José Ortega y Gasset en Ideas sobre la novela (1925), quien abogaba por la "psicología imaginaria" y la "invención de almas interesantes" (199 y 202), la vanguardia narrativa hispánica de ambos lados del océano siguió enfocada en los objetos, particularmente en las máquinas, y ante todo las máquinas en movimiento: trenes, tranvías, automóviles, aviones o barcos de vapor. Pero es precisamente el movimiento, a menudo vertiginoso de estas máquinas, así como su pertenencia a los espacios públicos, el que rompe el patrón realista de la "pura descripción inmóvil" que Ortega y Gasset le reprochaba a Proust (176).

La narrativa del boom latinoamericano construyó sus novelas totalizadoras sobre los cimientos de una refinada técnica de raíz vanguardista que, poniendo de relieve los artificios narrativos, parecía darles a las novelas el aspecto de una construcción mecánica o una arquitectura (esto a su vez alentaba lecturas "estructuralistas" como las de García Márquez por Ludmer y Vargas Llosa por Oviedo). Paradójicamente, sin embargo, en estas novelas de complicados engranajes narrativos, las circunstancias y ambientes por los cuales se movían sus personajes a menudo desplegaban un insistente arcaísmo que parecía desdeñar la tecnología, la ciencia e, incluso, el mundo de los objetos materiales.

Los objetos materiales en las novelas del boom tendían a convertirse en palabras y a disolverse en el lenguaje, en novelas autorreferenciales en las cuales los espacios eran fluidos y las relaciones entre múltiples personajes a través del tiempo eran más importantes que las cosas que los rodeaban. Aunque ciertamente los espacios urbanos de Buenos Aires, Ciudad de México, La Habana, Lima o París son muy visibles como escenarios en estas novelas, ¿ipodría alguien hacer un inventario detallado de la casona de los Buendía o un mapa preciso del propio Macondo? Los objetos materiales en las novelas del boom aparecen y desaparecen al servicio de la necesidad narrativa; aun cuando parezcan proliferar barrocamente, son solo palabras, nombres de cosas, alusiones, no objetos macizos y palpables que tengan un poder determinante en las vidas de los personajes. Significativamente, se podría argumentar que el único objeto material determinante en Cien años de soledad es el manuscrito de Melquíades, es decir, un libro que está a punto de desmoronarse, hecho de palabras cifradas escritas sobre unos "pergaminos $[\ldots]$ que parecían fabricados en una materia árida que se resquebrajaba como los hojaldres" (125).

No obstante, a partir del posboom, y en la narrativa actual de nuestro siglo XXI, se ha venido registrando una atención cada vez más intensa sobre lo que los antropólogos han dado en llamar cultura material y que en literatura se trata simplemente 
- si se me perdona el adverbio - de las cosas que enmarcan las vidas de los personajes y a las que nuevamente se les asigna una función que, si no es tan socialmente determinante como lo fue en el siglo XIX, no obstante es fuertemente simbólica. Aunque siguen asociadas a la identidad personal, como en el siglo XIX, las cosas en la narrativa latinoamericana del siglo XXI también se vinculan con la memoria histórica, al tema del tiempo y a la búsqueda de verdades colectivas e individuales. De hecho, como se aprecia con especial claridad en la novela del colombiano Juan Gabriel Vásquez, El ruido de las cosas al caer, la "entrada en materia" de la narrativa actual no parece tan distinta a la del siglo XIX, sobre todo si se la compara no tanto con la narrativa realista, sino con la poesía decimonónica, en particular con la estética del simbolismo francés y del modernismo hispanoamericano.

Importa señalar que la presencia de la poesía como tema y como elemento discursivo ha sido, a todas luces, una de las características sobresalientes de la novela hispanoamericana de principios del nuevo milenio, desde la recuperación de las poéticas vanguardistas en Los detectives salvajes (1999) de Roberto Bolaño y las evocaciones de la lírica japonesa en Mario Bellatin hasta el uso del narcocorrido mexicano en Trabajos del reino (2003) de Yuri Herrera, la incorporación de la poesía de Alejandra Pizarnik en La muerte me da (2008) de Cristina Rivera Garza y las traducciones de poesía romántica europea en El viajero del siglo (2009) de Andrés Neuman. Como veremos, en El ruido de las cosas al caer (cuyo título es un verso endecasílabo, como observa el propio autor en una entrevista; De Maeseneer y Vervaeke 212), las alusiones a la poesía del modernista colombiano José Asunción Silva y a la de su compatriota del siglo XX, Aurelio Arturo, resultan esclarecedoras acerca del papel que desempeña la cultura material en esta novela del siglo XXI.

El ruido de las cosas al caer, Premio de Novela Alfaguara 2011, narra la historia del profesor de leyes Antonio Yammara, cuya amistad forjada en un salón de billares con el exconvicto Ricardo Laverde lo lleva a confrontarse de manera directa con la violencia del narcotráfico en Colombia y sus consecuencias, al ser herido de bala en el atentado donde muere Laverde a principios del 1996. Mientras convalece de sus heridas, sufriendo además de un trastorno de estrés postraumático, Yammara comienza a investigar las causas del atentado que segó la vida de Laverde. Su investigación morosa y azarosa lo lleva a regresar al destartalado edificio de alquiler en el que vivía Laverde, donde obtiene un audiocasete que el exconvicto había estado escuchando con lágrimas en los ojos en la biblioteca de la Casa de Poesía Silva, poco antes de su muerte. El audiocasete contenía una grabación de la caja negra de un avión estrellado, en el cual regresaba a Colombia desde Estados Unidos Elena Fritts, la esposa norteamericana de Laverde separada de él hacía veinte años, y con la cual esperaba reencontrarse. 
Como resultado de su paso por el antiguo domicilio de Laverde, Yammara recibe varios meses después una llamada de Maya Fritts, la única hija de Elena y Ricardo, quien, al enterarse de las investigaciones del abogado, lo invita a visitarla en su finca situada entre Bogotá y Medellín para que la ayude a entender el pasado de su padre. En paralelo con esta trama principal de la novela, una trama secundaria relata el matrimonio consensual de Yammara con su antigua estudiante Aura, con la cual tiene una hija, Leticia, aunque la relación de pareja entre ambos ha decaído después del atentado. Así, sin decirle nada a su mujer, Yammara viaja a ver a Maya Fritts durante un fin de semana.

Durante esta visita, principalmente a través de cartas y otros documentos que le provee Maya, Yammara descubre que Laverde había trabajado durante años como piloto en el contrabando de marihuana a Estados Unidos desde Colombia hasta ser capturado por agentes de la DEA, en 1976, y condenado a diecinueve años de cárcel en Estados Unidos. De paso, Yammara encuentra que en los orígenes del narcotráfico entre Colombia y los Estados Unidos estuvo involucrado un individuo llamado Mike Barbieri, quien, como Elena Fritts, era miembro de los Cuerpos de Paz de ese país. (Este detalle, como era de esperarse, ha ocasionado algunas controversias entre los lectores estadounidenses al publicarse la traducción al inglés de la novela; ver Coyne.)

El fin de semana de Yammara con Maya Fritts culmina con el viaje de ambos a las ruinas de la Hacienda Nápoles, la finca y antiguo zoológico del narcotraficante colombiano Pablo Escobar, en un retorno nostálgico a un lugar que ambos habían visitado durante su niñez. Allí se topan sorprendidos con uno de los hipopótamos que, tras el cierre del zoológico, se han escapado y reproducido por la zona. La novela comienza, de hecho, con la noticia televisada acerca de la cacería y descuartizamiento de uno de estos hipopótamos, de modo que el viaje al zoológico cierra simbólicamente un ciclo de la trama. Tras un fallido escarceo erótico en su última noche de visita, Yammara y Maya escuchan juntos la grabación de la caja negra del avión accidentado de Elena Fritts y se sienten momentáneamente unidos no solo por aquella catástrofe, sino por toda la sórdida historia del narcotráfico colombiano a cuyos inicios asistieron los padres de Maya. Sin embargo, comprendiendo que el pasado común entre ambos no implicaba un común futuro, Yammara decide retornar a Bogotá a reunirse con Aura y Leticia, recordando los versos del poema "Ciudad de sueño", de Aurelio Arturo:

Yo os contaré que un día vi arder entre la noche una loca ciudad soberbia y populosa, yo, sin mover los párpados, la miré desplomarse, caer, cual bajo un casco un pétalo de rosa. (Vásquez 255) 
El tono apocalíptico de este poema queda mitigado por la escena final de la novela, en la cual Yammara, acostado en la cama vacía de su pequeña hija mientras espera la llamada de Aura con la cual tal vez podrán reconciliarse, contempla con esperanza y con temor "las formas y colores" de un juguete móvil "que se movían de manera imperceptible" sobre la cama (259).

Cosas que se mueven, gente que se inmoviliza: tal parece ser el patrón predominante de esta novela donde los objetos, las cosas, parecen estar (como sugiere el título) siempre en movimiento, incluso en caída libre, y donde la comprensión de muchos sucesos depende de poder trazar las trayectorias de esas cosas y de escuchar y poner luego por escrito el "ruido" que "hacen al caer". Una somera enumeración de cinco de los principales objetos simbólicos en la novela ilustra esta dicotomía entre lo que se mueve y lo inmóvil, y nos permite trazar una suerte de radiografía simbólica de la novela. El primero, en orden de aparición, es el hipopótamo escapado, un animal convertido en objeto de contemplación en el zoológico, que vuelve a su condición natural al fugarse y que deviene en un complejo símbolo que evoca fenómenos, como la globalización y el narcotráfico, así como la fiereza de un animal salvaje corpulento y torpe - como lo fue también su dueño, Escobar-. De hecho, la escena de la caza del hipopótamo a principios de la novela y la foto que se toman los cazadores junto al animal muerto evoca una foto grotescamente parecida que se tomaron los soldados del coronel Hugo Martínez alrededor del cadáver de Pablo Escobar en 1993 (13-14; Wikimedia Commons).

Otro objeto simbólico - esta vez inequívocamente una cosa, no un ser vivo "cosificado" - lo es la mesa de billar en torno a la cual se conocen el narrador y Ricardo Laverde. Esta y el juego que en ella se juega, con sus trayectorias, choques y carambolas, es otro símbolo pleno de sugerencias en torno a la función de la casualidad y su reverso, la causalidad, en el contexto tanto de la novela como del "mundo real".

La novela, además, destaca dos objetos básicos de transporte: el automóvil y el avión. El uso de automóviles por parte del narrador y los otros personajes principales sirve de base para descripciones detalladas de las carreteras colombianas y de la accidentada geografía del país, a la vez que marca, como lo hacían los objetos en la novela realista decimonónica, el cambiante estatus social de los personajes: recordemos el lujoso campero color marfil Nissan Patrol, modelo 68, que un día llega manejando a su casa Ricardo Laverde ante la mirada sorprendida de su esposa (181-183).

A su vez, dos aviones presiden sobre sucesos trágicos en el texto: el Boeing 757 en el que viajaba Elena Fritts de regreso a Colombia el último día de 1995 , el cual se estrella contra una montaña durante el descenso a Cali, y la avioneta 
Cessna 310-R que había pilotado Ricardo Laverde el día en que fue arrestado, una de las tantas que pilotó para el narcotráfico. Evidente símbolo ascensional, el avión es también un símbolo de riesgo, cuya ilusión de libertad y poderío (como se ve en las poéticas líneas donde Ricardo le explica a Elena la euforia que siente al volar, 186) se deshace con el más leve error humano (como se ve en el casete del accidente aéreo). Los aviones son también, por supuesto, parte imprescindible de la maquinaria de la globalización con la cual están entretejidas las vidas de los personajes de El ruido de las cosas al caer.

El quinto objeto, aparentemente pequeño y trivial, lo es el casete donde están grabadas las últimas palabras del piloto y copiloto y los sonidos del estrellamiento del vuelo de Elena Fritts. Sobre el mismo diré más al final de estas páginas.

Conviene anotar que estos objetos que he destacado dentro de la novela son parte de un paisaje más amplio de otros objetos también simbólicos, aunque tal vez de menor alcance: la canasta de recortes de revistas y cartas de Elaine que Maya conserva y le da a leer a Yammara; las colmenas de Maya, que es apicultora; el ya mencionado mobile de la pequeña Leticia, e incluso el "consolador" o vibrador violeta que Aura le compra a Antonio para tratar de reparar la vida sexual de ambos.

Estas "cosas" en las que la novela se fija especialmente,junto con el andamiaje de referencias históricas, políticas y geográficas que es típico del realismo, configuran una narración que abunda en correspondencias y en patrones que invitan a leer la novela no solo en clave lírica e intimista (lo cual es un factor importante de su tono), sino como el desciframiento de un mensaje soterrado dentro de una constelación de símbolos que se "llaman" oscuramente los unos a los otros dentro del texto como en el forêt de symboles del célebre soneto de Baudelaire.

El texto de El ruido de las cosas al caer contiene múltiples alusiones a la estética simbolista, encarnada sobre todo en referencias a la obra de José Asunción Silva, el mayor poeta del modernismo colombiano. Recordemos que poco antes de ocurrir el atentado contra Laverde, Yammara lo había llevado a la cercana Casa de Poesía Silva (verdadera institución cultural situada en la casa donde había vivido y se había suicidado el poeta, en el barrio bogotano de La Candelaria) para utilizar allí unas grabadoras con audífonos en la Biblioteca de la Casa con las cuales Laverde pudiera escuchar un misterioso casete. Laverde oye el casete y Yammara, que se ha puesto a oír una grabación del "Nocturno III" de Silva, se da cuenta de que su amigo llora al escucharla. ${ }^{2}$ Queriendo ser discreto, Yammara

2 Si bien es cierto que Yammara evoca el tan traído y llevado "Nocturno" de Silva, pienso que la evocación general de este gran modernizador de la poesía colombiana bien puede extenderse al conjunto de su obra, y entonces sería legítimo traer a este contexto poemas de Silva como "Veje- 
cierra los ojos mientras escucha los versos de Silva, y cuando los abre, Laverde ya se ha ido. Al salirlo a buscar, Yammara lo alcanza a dos cuadras de los billares a la misma vez que recuerda uno de los versos del "Nocturno": "Y eran una sola sombra larga...", y entonces ocurre el atentado (44-49). Todo esto sucede a principios de 1996, año cuando se conmemoraba la muerte de José Asunción Silva mediante un ruidoso homenaje nacional.

Como se sabe, la idea del símbolo está predicada sobre la supuesta correspondencia unívoca entre el símbolo (que se deriva siempre de un objeto material) y su significado (el concepto que el símbolo representa) dentro de una cultura y una época específicas: así, en la cultura occidental, el león ha sido por mucho tiempo un símbolo de valentía; la rosa roja, símbolo del amor, etcétera. El simbolismo decimonónico, como nos recuerda Octavio Paz en Los hijos del limo (1974), se basaba en la creencia de que todos los objetos materiales del universo pueden ser símbolos, y de que existe un principio de "analogía universal" que gobierna la relación entre los símbolos y los conceptos que estos representan.

Pienso que la diferencia entre el simbolismo de fines del siglo XIX y el que practica aquí Juan Gabriel Vásquez reside precisamente en la movilidad, el dinamismo de este último. En la estética simbolista y modernista, las figuras del museo y del interior son espacios clave en los cuales se inmovilizan las cosas y se las contempla para intentar descifrar los vínculos, a menudo, secretos entre ellas. Como nos lo evocan los versos del poema "Vejeces" de Silva, las antiguallas, bibelots, chinerías y japonerías del interior modernista, escudriñadas por el coleccionista finisecular que va descifrando y disfrutando sus detalles, no conducen tanto al conocimiento, sino más bien al ensueño, al ensimismamiento y a la nostalgia, además de proveerle al coleccionista la ilusión de tener control sobre el mundo protoglobalizado de donde provienen muchos de estos objetos.

En El ruido de las cosas al caer, por el contrario, los objetos simbolizantes no permanecen estáticos y no se relacionan mediante misteriosas simpatías; en cambio, su desciframiento requiere que se sigan y persigan las trayectorias mediante las cuales los símbolos chocan y entran en contacto los unos con los otros. (Llama la atención el hecho de que lo más parecido a un museo que se ve en esta novela lo es el arruinado zoológico del narco Escobar, cuyos animales se han fugado a la selva.) La interpretación de los símbolos no busca aquí producir

ces" (que he citado como epígrafe), el cual, desde una perspectiva filológica y casi museográfica, subraya el papel de los objetos materiales como depósitos de la memoria histórica. Y tampoco hay que olvidar que el fino poeta de El libro de versos (1896) fue también el irónico y sarcástico versificador de las Gotas amargas, donde adopta una postura fuertemente materialista. 
ensueño ni nostalgia, sino la revelación de verdades, con frecuencia verdades más personales que colectivas. Al privilegiar la presencia de ciertos objetos materiales en su narración, el narrador va más allá de su significado convencional para revestirlos de un significado personal, intentando convertirlos en símbolos nuevos para una época nueva.

Ahora bien, la dificultad en poder observar y "leer" las cosas para tornarlas en símbolos reside precisamente en su constante movimiento, el cual plantea el problema de su cercanía o su lejanía. En este sentido, El ruido de las cosas al caer parece evocar las reflexiones de Heidegger en su conocido ensayo "La cosa" (1950), en el cual el pensador alemán sitúa la definición del concepto cosa en el contexto de un mundo que hoy llamaríamos globalizado. En este mundo, las distancias se han reducido hasta casi borrarse, pero —-según arguye Heidegger desde su perspectiva esencialista - esta reducción espacial no se ha convertido en verdadera cercanía. Ello sucede porque nuestras formas de representación tanto en las artes como en las ciencias - nunca nos dan acceso a la "cosidad de la cosa", pues al intentar acercarnos a las cosas para verlas mejor, solo conseguimos percibirlas en aspectos a veces radicalmente distintos: en su famoso ejemplo de la jarra, Heidegger plantea que si desde una perspectiva filosófica la jarra como recipiente puede verse como una forma determinada por el vacío, por una ausencia que es necesario llenar, desde la perspectiva científica la jarra siempre está llena de algo, sea vino o sea aire (147). La solución cuasi religiosa que propone Heidegger a esta paradoja, evocando la raíz germánica de la palabra Ding (que significaba reunión, así como asunto o preocupación) es que la cosa es un lugar de reunión, un compuesto o punto de contacto entre la ausencia y la presencia, lo físico y lo metafísico (151-154).

El ruido de las cosas al caer se escribe, por supuesto, desde una perspectiva de las cosas que ya hace tiempo dejó de ser esencialista, y lo único que tiene en común con la formulación de Heidegger es la idea de la cosa como compuesto o punto de reunión de múltiples perspectivas. Se trata, entonces, de una visión dinámica de los objetos y su significado, donde el significado simbólico de las cosas es producto de una suerte de consenso o mutuo acuerdo, una "reunión", si se quiere, de dos o más subjetividades. De ahí la importancia que reviste para la trama de esta novela la reunión de Antonio Yammara y Maya Fritts durante un fin de semana en el cual ambos pasan revista a un conjunto de cosas, de asuntos, que los vinculan entre ellos y, a la vez, los conectan con la historia reciente de su nación.

Si la poesía de Silva preside el primer capítulo de la novela, el último evoca la de Aurelio Arturo. Poeta de trayectoria única e idiosincrásica en Colombia, no afiliado ni afiliable a las agrupaciones de poetas que le fueron contemporáneas 
(como los piedracielistas; Arturo 313 y 373), Aurelio Arturo ha sido visto como un prolongador del legado de Silva. Como apunta Ramiro Pabón, la "melodía de ensoñación, apagada y difusa de Arturo que tanto complace y asombra al buen lector, está emparentada con la que empleó José Asunción Silva en sus mejores poemas" (Arturo, 2003, 155, 389). A diferencia del modernista, sin embargo, la poesía de Arturo, según plantea Óscar Torres Duque, está más atenta a las realidades concretas que a las vagas correspondencias al estilo de Baudelaire y Verlaine (Arturo, 2003, 389). La crítica de Arturo también destaca el hecho de que en su libro Morada al sur los elementos del paisaje colombiano no son meramente decorativos sino que son "materia misma de las palabras" (Arturo 126 y 406). La poesía de Arturo ha sido elogiada además por su musicalidad muy cercana al canto, por su celebración de la infancia y por su tendencia totalizadora (385). Resultan muy sugestivas en este particular las observaciones de Torres Duque acerca del "carácter narrativo" de esa poesía, el cual se expresa, paradójicamente, de modo atemporal, concentrado en el "presente puro" del acto de narrar (Arturo 405-406) - paradoja que nos recuerda la del móvil que se movía "de manera imperceptible" (Vásquez 259) sobre la cama de Leticia en las últimas páginas de la novela de Vásquez-. Podría incluso argumentarse que El ruido de las cosas al caer está escrito desde una perspectiva ampliamente influida por el tono poético de Aurelio Arturo si se toma en cuenta, como observa la crítica del poeta de Nariño, que la narratividad en la poesía de Arturo se expresa como una especie de serena reconciliación con la historia, con los hechos a veces traumáticos del pasado. Como observa Torres Duque:

[L]a actitud fundamental narrativa [de Arturo] es el relajamiento, la laxitud, y eso le permite al poeta narrador encarar cualquier realidad, de su vida o la de otros, sin la inevitable carga de dramatismo que conlleva en tanto hecho vivido. Así, el "espanto", por ejemplo, de las noches de su infancia, no crea en el cantor maduro [...] un trauma o conflicto que lo obligue a exaltar su ánimo para contar la historia, sino que es asumido como hecho cantado y por tanto conjurado, relajado, placentero incluso, como aquello que habiendo sido terrible es ahora motivo de realización humana, de humano conocimiento. (Arturo 405)

Una operación reconciliadora semejante se aprecia mientras Yammara maneja de regreso a Bogotá, y sus pensamientos y recuerdos se entremezclan con los versos del poema de Arturo "Ciudad de sueño", glosando una estrofa del poema: Ardía como un muslo entre selvas de incendio, y caían las cúpulas y caían los muros 
sobre las voces queridas tal como sobre espejos

amplios...jdiez mil chillidos de resplandores puros!

$[\ldots]$

Yo iba pensando en todo lo que había escuchado en el fin de semana y en la mujer que me lo había contado, y también en lo que había visto en la Hacienda Nápoles, cuyas cúpulas y cuyos muros también habían caído, y también, por supuesto, iba pensando en el poema de Arturo y en mi familia, en mi familia y el poema de Arturo, en mi ciudad y el poema y mi familia, las voces queridas del poema, la voz de Aura y la voz de Leticia, que habían llenado mis últimos años, que en más de un sentido me habían rescatado. (255-256)

En este contexto, el simbolismo del más pequeño y al parecer trivial de los objetos que se nombran en la novela se expande y enriquece: el casete que, en copias distintas, escuchan tanto Laverde como Yammara y Maya. El casete es un evidente sucedáneo de la escritura, es otra forma de escritura, en la cual se conserva y reproduce la dimensión sonora y se reduce al mínimo la visual. Asociado en este caso a la "caja negra" del avión siniestrado, el casete, como la escritura, solo puede dar evidencia indirecta sobre lo que más les importa a quienes lo escuchan en la novela (Laverde, Yammara y Maya): los últimos momentos de Elena Fritts.

El casete, propongo, es un símbolo de la propia novela en la cual se encuentra, específicamente de la poética implícita de la novela que nos propone Juan Gabriel Vásquez en esta obra: se trata de la novela vista como casete, como grabación o registro de algunos hechos, o más precisamente de los sonidos que acompañan a los hechos. Escribir es registrar sonidos, el "ruido" de las cosas; leer es atender a esos sonidos y con ellos reconstruir las cosas separadas y fragmentadas por la distancia, para devolverles, o quizá inventarles, su forma. Si la poesía, como nos dice la preceptiva, es una invitación a darles forma a las cosas, la presencia de la poesía en esta novela apunta a la tarea siempre retadora que afronta el novelista de buscar darle forma al más informe de los géneros literarios. Más aún, la pequeñez y el carácter reproducible del casete, el precursor no tan remoto de nuestros medios digitales, sugiere que para Juan Gabriel Vásquez la "cosidad" de la novela depende menos de su soporte material - ya sea libro, casete o audiolibro - que del patrón de sonidos, el diseño repetible que puede dársele a las "palabras volanderas" para que, en su caída libre, ellas nos puedan comunicar su urgente mensaje. 


\section{Obras citadas}

Arturo, Aurelio. Obra poética completa. Coord. Rafael Humberto

Moreno-Durán. Nanterre: Alica XX, 2003. Impreso.

Brooks, Peter. Realist Vision. New Haven: Yale University Press, 2008. Impreso.

Coyne, John. "Colombia PGVs Damaged by Juan Gabriel Vasquez Novel, The Sound of Things [sic]". Peace Corps Worldwide. Web. 10 de febrero de 2015.

"Death of Pablo Escobar". Wikimedia Commons. Imagen web. 10 de febrero de 2015.

De Maeseneer, Rita y Jasper Vervaeke. "Un fósforo en la oscuridad: conversación con Juan Gabriel Vásquez". Confluencia 28 (2013): 209-216. Impreso.

García Márquez, Gabriel. Cien años de soledad. Madrid: Espasa-Calpe, 1993. Impreso.

Heidegger, Martin. "La cosa". Conferencias y artículos. Trad. Eustaquio Barjau. Barcelona: Del Serbal, 1994. 143-162. Impreso.

Ludmer, Josefina. Cien años de soledad: una interpretación. Buenos Aires: Tiempo Contemporáneo, 1972. Impreso.

Ortega y Gasset, José. Meditaciones del Quijote e ideas sobre la novela. Madrid: Revista de Occidente, 1975. Impreso.

Oviedo, José Miguel. Mario Vargas Llosa: la invención de una realidad. Barcelona: Barral, 1970. Impreso.

Paz, Octavio. Los hijos del limo. Barcelona: Barral, 1974. Impreso.

Silva, José Asunción. Obra completa. Eds. Eduardo Camacho Guizado y Gustavo Mejía. Caracas: Biblioteca Ayacucho, 1977. Impreso.

Vásquez, Juan Gabriel. El ruido de las cosas al caer. Madrid: Santillana, 2011. Impreso.

Woolf, Virginia. "Modern Fiction". Collected Essays II.

Londres: Hogarth Press, 1966, 104-107. Impreso. 